\title{
Deliberately light interpersonal contact affects the control of head stability during walking in children and adolescents with cerebral palsy
}

Katrin Hanna Schulleri ${ }^{1}$, Frauke Burfeind ${ }^{2}$, Beate Höß-Zenker ${ }^{3}$, Éva Feketené Szabó ${ }^{4}$, Nadine Herzig $^{5}$, Annick Ledebt ${ }^{2 a}$, Leif Johannsen ${ }^{1,6}$

${ }^{1}$ Department of Sport and Health Science, Technische Universität München, Munich, Germany

${ }^{2}$ Department of Human Movement Sciences, VU University Amsterdam, Amsterdam, The Netherlands

${ }^{2 a}$ MOVE Research Institute Amsterdam, Amsterdam, The Netherlands

${ }^{3}$ Phoenix GmbH, Konduktive Förderung der Stiftung Pfennigparade, Munich, Germany

${ }^{4}$ András Pető College, Budapest, Hungary

${ }^{5}$ Zentrum für Kinder- und Neuroorthopädie, Schön Klinik München Harlaching, Munich, Germany

${ }^{6}$ School of Health Sciences, University of East Anglia, Norwich, United Kingdom

Running head: Interpersonal contact in individuals with CP

Corresponding Author:

Leif Johannsen, Dr rer nat, Dipl-Psych

School of Health Sciences, Faculty of Medicine and Health Sciences, University of East

Anglia, Norwich Research Park, Norwich, NR4 7TJ, United Kingdom

Email: L.Johannsen@uea.ac.uk

Tel.: +441603 593318 
Interpersonal contact in individuals with $\mathrm{CP}$

\section{Acknowledgements}

We acknowledge the financial support by the Federal Ministry of Education and Research of Germany (BMBF; 01EO1401) and by the Deutsche Forschungsgemeinschaft (DFG) through the TUM International Graduate School of Science and Engineering (IGSSE). 
Interpersonal contact in individuals with $\mathrm{CP}$

Deliberately light interpersonal contact affects the control of head stability during walking in children and adolescents with cerebral palsy

Word limit: 3000 including abstract (current: 2800)

Abstract word limit: 200 (current: 199)

Figure limit: 4 (current: 2)

Reference limit: 25 (current: 22)

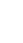

\section{Abstract}

OBJECTIVE To evaluate the potential of deliberately light interpersonal touch (IPT) for reducing excessive head and trunk sway during self-paced walking in children and adolescents with cerebral palsy (CP).

DESIGN Quasi-experimental, proof-of-concept study with between-groups comparison.

SETTING Ambulant care facility, community center.

PARTICIPANTS 26 individuals with CP (spastic and ataxic; GMFCS I-III; mean=9.8y; $\mathrm{f}=11, \mathrm{~m}=15)$ and in 39 typically developed (TD) children and adolescents (mean=10.0y; $\mathrm{f}=23, \mathrm{~m}=16)$.

INTERVENTIONS IPT applied by a therapist to locations at the back and the head.

MAIN OUTCOME MEASURES As primary outcomes head and trunk sway during selfpaced walking were assessed by inertial measurement units. Secondary outcomes were average step length and gait speed.

RESULTS CP group: apex and occiput IPT reduced head velocity sway compared to thoracic IPT (both $\mathrm{p}=0.04$ ) irrespective of individuals' specific clinical symptoms. TD group: all testing conditions reduced head velocity sway compared to walking alone (all $p \leq 0.03$ ) as well 
Interpersonal contact in individuals with CP

26 as in apex and occiput IPT compared to paired walking (both $\mathrm{p} \leq 0.02$ ).

27 CONCLUSIONS Deliberately light IPT at the apex of the head alters control of head sway

28 in children and adolescents with CP. The effect of IPT varies as a function of contact location

29 and acts differently in TD individuals.

30 KEY WORDS: Cerebral palsy, Locomotion, Interpersonal touch, Body sway

31

32

Highlights

33

34 - Apex IPT alters locomotor control of head sway in CP.

35 - Trunk IPT acts in opposition to head IPT in CP.

36

- IPT affects TD individuals differently than individuals with CP.

37 
Severe gait deficits in individuals with cerebral palsy (CP) lead to increased fall risk with disabilities in activities of daily living and reduced social participation ${ }^{1}$. During walking, the motion of the trunk as the heaviest segment of the body strongly affects the locomotor pattern and requires active balance control. ${ }^{2}$ Individuals with CP show severe gait disorder in combination with noticeable abnormalities in trunk motion, which may be a genuine deficit and specific cause for gait instability in $\mathrm{CP}^{3,}{ }^{4}$ Impaired gross motor function is associated with greater thorax range of motion during walking in $\mathrm{CP} .{ }^{5}$ Heyrman et al. ${ }^{6}$ reported that children with spastic diplegia and just mildly impaired gross motor function still show increased lateral bending of the trunk during gait, while more severely impaired children demonstrate increased motion amplitude in all three spatial planes.

Any trunk motion during walking will perturb head orientation and thus cause significant vestibular stimulation unless neck articulation minimizes head motion. Compensatory headon-trunk articulation during walking primarily serves head stability. ${ }^{7}$ Minimizing head motion may therefore be a major goal of the postural control system during walking in order to align the horizontal semi-circular canals of the vestibular system to the earth horizontal for facilitating the integration of vestibular and visual information. ${ }^{8}$

It is an open question how trunk control can be improved in children with CP. Vision and vestibular feedback play an important role but they are not the only afferent signals that can be used for locomotor control. Somatosensory afferences as well as proprioceptive feedback are also employed for controlling the gait cycle and body balance. ${ }^{9}$ A review by Pavão and

60 colleagues, ${ }^{10}$ indicated lacking research on the benefit of somatosensory feedback for balance control in individuals with CP. 
63 Researchers have become increasingly interested in the effect of non-plantar light tactile 64 feedback on body control when contacting an external reference. The effect of light touch during standing and walking has been described in several patient populations. ${ }^{11}$ In addition to the single-person concept of haptic sensory augmentation, interpersonal touch (IPT) is a

67 category of haptic interactions very relevant and frequently used in clinical situations.

68 Deliberately light IPT results in reduced sway and increased coordination of trunk sway 69 between two individuals during quiet standing as well as voluntary swaying. ${ }^{12,13}$ IPT reduces sway in patients with chronic stroke as well as Parkinson's disease. ${ }^{14}$ More rostral IPT (at shoulder level) reduces sway to a greater amount than more caudal (low back) locations, ${ }^{14}$ which is analogous to single-person effects of light touch on body sway. ${ }^{15,16}$ The observation that more cranial IPT results in more reduced sway could be caused by a clearer signal due to greater sway amplitude at the contact point. Alternatively, an increased resemblance between the haptic and vestibular signals could facilitate more accurate stability state estimation. ${ }^{17}$

This proof-of-concept study aimed to investigate the effect of IPT on the control of trunk sway and gait during walking in children and adolescents with cerebral palsy. In order to assess the effects of IPT on locomotion without confounding movement impairments caused by $\mathrm{CP}$, age-matched typically developed participants were tested. We hypothesized that

81 reinforcement of the head as an inertial guidance platform ${ }^{8,18}$ by IPT at more rostral locations 82 would benefit the control of head and trunk sway in participants with and without CP.

Method

\section{Participants}

87 A convenience sample of twenty-six children and adolescents (age: mean=9.8 years, SD 4.5; 
height: mean=134 cm, SD 22; weight: $34.3 \mathrm{~kg}$, SD 18.5) with CP were recruited at three therapeutic institutions (Schön Klinik Harlaching, München; Phoenix Pfennigparade, München; Petö Institute, Budapest). Participants with CP needed a Gross Motor Function Classification System (GMFCS) ${ }^{18}$ level of III or higher to participate. Individuals were excluded if any other impairments were reported that could either affect locomotion or communication. Another convenience sample of thirty-nine typically developed individuals (age: mean=10.0 years, SD 4.4; height: mean=144 cm, SD 25; weight: $38.5 \mathrm{~kg}$, SD 17.5) were recruited from the community as a control group. Table 1 shows the demographic and clinical information of all participants. The study was approved by the medical ethical committee of the Technical University of Munich and all participants or their guardians respectively gave written informed consent.

\section{--- Insert Table 1 about here ---}

\section{Experimental procedure}

Each participant took part in a single testing session of 45 minutes duration. After demographic and medical data were collected the child was familiarized with an inertial motion tracking system (Xsens MTw, Enschede, The Netherlands). Four sensors of the system $(60 \mathrm{~Hz})$ were fastened to both lower legs laterally, sternum, and forehead. Following two practice trials, each participant walked at self-chosen pace in a straight line a distance of $10 \mathrm{~m}$ between two measured floor markings six times per testing condition. Participants were tested in five testing conditions in randomized order. IPT was applied by either a physical therapist or a conductor in three conditions, while in the remaining two control conditions participants walked without IPT: (I) walking alone, (II) walking with the physical therapist/conductor peripherally visible (paired walking), (III) IPT on the thoracic spine 
113 (between the scapulae), (IV) below the occiput, and (V) slightly dorsal of the apex of the

114 head. An overview of the IPT locations is presented in Figure 1a.

\section{Data reduction}

119 Orientation of the inertial sensors in all three planes was processed unfiltered by a custom

120 processing toolbox in Matlab (2014a). Phases of steady-state walking were extracted by

121 manually segmenting trials based on sensor data from the dominant leg to exclude turning

122 points, gait initiation and stopping from analysis. Gait speed and average step length were

123 determined by dividing the walking distance by the time needed to cover it and the number of 124 all steps detected during this period.

126 Head and trunk velocity sway (HVS, TVS) were measured as the standard deviation of the 127 angular velocity of the respective sensor's orientation. In order to prevent angular flip-overs 128 between $-180^{\circ}$ to $180^{\circ}$ from distorting the velocity sway measure, sensor orientation angles

129 were cosinus-transformed before differentiation $(\cos (\alpha) / \mathrm{s}$; Fig. 1b). A direction-unspecific

130 velocity sway measure was calculated for each sensor by taking the square-root of the sum of squares of the velocity sway on each of the three axes of a sensor.

\section{Statistical analysis}

134 Statistical analysis was performed in IBM SPSS statistics 23. All extracted parameters (gait

135 speed, step length, head and trunk velocity sway) were statistically analyzed using a mixed 136 two-factorial repeated-measures ANOVA with group as the between-subject factor (2 levels:

137 CP vs TD participants) and testing condition as the within-subject factor (5 levels). Due to the 
Interpersonal contact in individuals with $\mathrm{CP}$

138 participants' range in demographic parameters such as age, height and weight, we used

139 independent T-tests as well as Chi-square tests to assess differences in the sample averages

140 and distributions between both participant groups. The TD group tended to be taller by about

$14110 \mathrm{~cm}(\mathrm{t}(63)=1.70, \mathrm{p}=0.09 ; \operatorname{Chi}(3)=8.25, \mathrm{p}=0.04)$. Therefore, we included height as a

142 covariate in all analyses encompassing a comparison between both groups. Greenhouse-

143 Geisser-corrected p-values were used as a conservative statistical criterion. Level of

144 significance was set to $\mathrm{p}=0.05$. Bonferroni-corrected post-hoc comparisons between

145 conditions were conducted as appropriate to resolve interactions between group and testing

146 condition.

147 Additional statistical analyses were performed between subgroups of the CP participants

148 according to GMFCS level (I/II/III) and impairment categorizations (spastic/ataxic; plegia:

149 unilateral/bilateral leg/bilateral arm/bilateral complete). No differences between subgroups of

150 the CP individuals were found with respect to age, height or weight with the exception that

151 the individuals with ataxic CP were numerically younger and shorter in height (both $\mathrm{p} \geq 0.11$ ).

\section{Results}

\section{Gait speed and stride duration}

156 Spontaneous gait speed was slower in the CP group (mean=1.03 m/s, SD 0.29;

$157 \mathrm{~F}(1,63)=13.60, \mathrm{p}=0.001$, partial $\left.\mathrm{eta}^{2}=0.19\right)$ than in the TD group (mean=1.32 m/s, SD 0.26).

158 An interaction between group and testing condition was found $(F(4,252)=15.36, p<0.001$,

159 partial $\mathrm{eta}^{2}=0.21$ ). In the CP group, the participants did not change their gait speed in any of

160 the testing conditions. In contrast, the TD group walked slower in all four conditions

161 compared to walking alone (mean $=1.41 \mathrm{~m} / \mathrm{s}, 0.27 \mathrm{SD}$; all $\mathrm{p} \leq 0.002)$. Gait speed was still

162 slower in occiput IPT (mean=1.25 m/s, SD 0.26) compared to thoracic IPT (mean=1.30 m/s, 
SD 0.26 ) and paired walking (mean $=1.34 \mathrm{~m} / \mathrm{s}$, SD 0.27 ; both $\mathrm{p} \leq 0.02$ ).

Average step length was shorter in the $\mathrm{CP}$ group (mean=50 cm, SD 10; F(1,63)=13.84,

$166 \mathrm{p}<.001$, partial eta ${ }^{2}=0.20$ ) compared to the TD group (mean=62 cm, SD 11). We also found

167 an interaction between the group and testing condition $(F(4,252)=9.30, p<0.001$, partial

168 eta $\left.^{2}=0.14\right)$. While no differences between testing conditions were found for the CP group, in the TD group step length was shorter in all four test conditions involving the physical therapist/conductor compared to walking alone (mean $=65 \mathrm{~cm}$, SD 11; all $\mathrm{p} \leq 0.03$ ). Thoracic (mean $=60 \mathrm{~cm}, \mathrm{SD} 12)$ and occiput IPT (mean=59 cm, SD 12) showed still shorter step length 172 relative to paired walking (mean $=63 \mathrm{~cm}, \mathrm{SD} 12$; both $\mathrm{p} \leq 0.006$ ).

For step length and gait speed no general differences between subgroups or interactions with the testing condition were found for the subdivisions of the CP participants. Exceptions were GMFCS level I tending to show the fastest gait speed (mean=1.17 m/s, SD 0.27) followed by

177 level II (mean=1.02 m/s, SD 0.22) and level III (mean=0.82 m/s, SD 0.41; F(2,23)=2.52,

$178 \mathrm{p}=0.10$, partial $\left.\mathrm{eta}^{2}=0.19\right)$.

179

\section{Head and trunk velocity sway}

181 HVS was greater in the CP participants $\left(F(1,63)=15.98, p<0.001\right.$, partial eta $\left.^{2} \geq 0.21\right)$ compared

182 to the TD group (Fig. 2a). TVS only tended to be greater in the CP participants than the TD

183 group $\left(F(1,63) \geq 3.04, p=0.09\right.$, partial eta $^{2} \geq 0.05$; Fig. $\left.2 b\right)$. For HVS and TVS, interactions were found between group and testing condition (both $F(4,252) \geq 3.54$, both $p \leq 0.03$, both partial eta $^{2} \geq 0.06$ ). In the CP group, HVS was reduced in the occiput and apex IPT conditions compared to thoracic contact (both $\mathrm{p} \leq 0.04$ ). Concerning the trunk, the thoracic IPT condition

187 tended to show more TVS than apex IPT $(p=0.06)$. In the TD group, all other conditions 
188 showed less HVS compared to walking alone (all $\mathrm{p} \leq 0.03$ ). In addition occiput and apex IPT were still lower than paired walking (both $\mathrm{p} \leq 0.02$ ). For the trunk, both apex and thoracic IPT tended to show lower TVS compared to walking alone (both $\mathrm{p} \leq 0.09$ ).

194 The CP subgroups differed in terms of HVS but no interactions between testing conditions and subgroups were found for either HVS or TVS. As an exception, an effect of GMFCS level on TVS was present $\left(\mathrm{F}(2,23)=3.60, \mathrm{p}=0.05\right.$, partial eta $\left.^{2}=0.25\right)$. The participants with

197 GMFCS level III showed the most variable TVS (mean=0.45, SD 0.15) followed by level II 198 (mean=0.29, SD 0.17) and level I (mean=0.21, SD 0.15).

\section{Discussion}

202 We aimed to investigate whether IPT at the head is a way to facilitate the control of body sway during walking in children and adolescents with CP and with typical development. The effect of IPT was assessed in terms of step length, gait speed as well as head and trunk velocity sway. In general, the $\mathrm{CP}$ and $\mathrm{TD}$ groups differed in gait speed and average step length. The TD group walked faster with longer average steps and less head and trunk velocity sway than the CP group. This is not unexpected as it is well known that individuals

208 with CP show reduced gait speed with longer stride duration and increased postural 209 instability.

211 Although our results did not exactly turn out as hypothesized, our study yielded some

212 interesting findings. The participants with CP showed less HVS with apex and occiput IPT in 
213 contrast to thoracic IPT. Numerically, these two conditions tended to differ from the two

214 control conditions walking alone paired walking in opposite directions with reduced HVS

215 during apex IPT. Nevertheless, it shows that the location at which IPT is applied to the

216 receiver's body does matter in CP. In contrast, the TD group showed lowest HVS in occiput

217 and apex IPT compared to both walking alone and paired walking. Further, while the CP

218 group did not walk with measurably changed speed, the TD group walked with reduced speed

219 by taking shorter average steps in the IPT conditions.

220

221 We assumed that IPT at the head facilitates the role of the head as an inertial guidance 222 platform for locomotion, improves control of trunk sway and optimizes gait in CP. In this 223 respect, only the TD group behaved in correspondence with our expectations. They showed least HVS in both head contact conditions and a small corresponding reduction in TVS. This indicates that the control of head sway became more influenced by a head-centric sensory signal compared to thoracic IPT or walking without IPT.

228 The CP group did not demonstrate any effect of the presence of the physical therapist/conductor. In contrast, the TD participants reduced HVS during paired walking, which may be the result of some form of 'social facilitation', perhaps by some form of spontaneous interpersonal entrainment of the stepping pattern between the physical

232 therapist/conductor and participant. The difference between the groups could mean that the

233 CP group was insensitive to or unable to comply with the social demands and constraints of interpersonal coordination.

236 With respect to human ontogenetic locomotor development, it was proposed that selective 237 control of the neck's movement degrees of freedom is a key feature of a mature upper body 
238 gait pattern. ${ }^{19}$ Wallard and colleagues observed an 'en bloc' head-on-trunk strategy with 239 increased head angle variability in the frontal plane during walking in children with CP and 240 proposed that it might express an 'en bloc' compensatory strategy by deliberate reduction of

241 the neck's movement degrees of freedom. ${ }^{20}$ As we found subtle effects of apex IPT in the CP 242 group, we speculate that apex IPT may still be a therapeutic approach to open up a habitual

243 'en bloc' strategy and to enable the exploration of neck articulation as well as the benefits of 244 actively stabilized head orientation. Advocates of a 'hands-off' approach ${ }^{21}$ emphasize 245 unrestricted self-exploration of the movement repertoire by the patient. We perceive 246 deliberately light IPT as a married form between 'hands-on' and 'hands-off' due to the low 247 contact forces involved and the absence of active restriction. The 'guidance' in IPT is 248 considered less physical but more implicit to the social context.

249 We did not find any differences between symptom subgroups among the participants with CP, which indicated that differences in symptoms did not alter the susceptibility to IPT and its social context. Visual inspection of our data showed that the responsiveness of the individuals with CP showed a high degree of inter-individual variability. As only two IPT providers were involved in data collection, it is unlikely that variability in the way IPT was applied caused this. Instead, factors within the CP individuals must be the reason, for example current motor competence in the control of trunk sway and neck articulation. The observation that more impaired individuals with CP, as indicated by their GMFCS level, performed worse was to be expected. It shows, however, that the capacity to respond to IPT is not determined by the general impairment level.

\section{Study limitations}

262 It might appear as a limitation, that the sway variability measures used in our study do not 
represent positional variability. Variability of angular velocity, however, is closer related to the control of body balance during locomotion. Differentiation of a signal acts as a high-pass filter, which removes low-frequency drift, which could occur in the absence of any positional control. For example, Allum and Carpenter $^{22}$ recommended measurements of trunk angular velocity as means to differentiate between specific control deficits of body balance.

We did not restrict our recruitment to participants with $\mathrm{CP}$ showing specific symptoms although this could have made our results more generalizable for this symptom subgroup. Our intention was to evaluate the general feasibility of IPT in a wide spectrum of symptoms.

272 The present study aimed to advance the understanding of the 'mechanisms of action' of IPT

273 for balance support during walking in individuals with $\mathrm{CP}$ and thus was designed as a single session, proof-of-concept study. The long-term benefits of deliberately light IPT during locomotor training in $\mathrm{CP}$ remain speculative at this point and therefore require a properly designed multi-session intervention study.

\section{Conclusions}

Deliberately light interpersonal contact applied to the apex of the head results in a reduction of head velocity sway compared to thoracic IPT during walking in children and adolescents with CP irrespective of their symptoms. This implies that the effect of IPT depends on the location at which it is applied in individuals with CP. The CP group, however, did not act in the same way as the TD group. TD individuals were much more responsive in terms of reductions in head velocity sway due to the presence of the therapist and the application of IPT. The difference may be an expression of reduced sensitivity regarding the social 
Interpersonal contact in individuals with CP

288 the ability to adapt behaviour to external social conditions. Further research is still required to 289 assess any longer-term benefits of IPT in individuals with CP.

290

291 
Interpersonal contact in individuals with $\mathrm{CP}$

292

293

294

295

296

297

298

299

300

301

302

303

304

305

306

307

308

309

310

311 plane during locomotor tasks. Physiotherapy research international : the journal for

312 researchers and clinicians in physical therapy 2004;9(1):33-42.

313 8. Pozzo T, Berthoz A, Lefort L, Vitte E. Head stabilization during various locomotor

314 tasks in humans. II. Patients with bilateral peripheral vestibular deficits. Exp Brain Res

315

316

\section{References}

1. dos Santos AN, Pavao SL, de Campos AC, Rocha NA. International Classification of Functioning, Disability and Health in children with cerebral palsy. Disability and rehabilitation 2012;34(12):1053-8.

2. Kavanagh JJ, Barrett RS, Morrison S. Upper body accelerations during walking in healthy young and elderly men. Gait Posture 2004;20(3):291-8.

3. Schweizer K, Brunner R, Romkes J. Upper body movements in children with hemiplegic cerebral palsy walking with and without an ankle-foot orthosis. Clinical biomechanics (Bristol, Avon) 2014;29(4):387-94.

4. Heyrman L, Feys H, Molenaers G, Jaspers E, Monari D, Nieuwenhuys A et al. Altered trunk movements during gait in children with spastic diplegia: compensatory or underlying trunk control deficit? Research in developmental disabilities 2014;35(9):2044-52.

5. Attias M, Bonnefoy-Mazure A, Lempereur M, Lascombes P, De Coulon G, Armand S. Trunk movements during gait in cerebral palsy. Clinical biomechanics (Bristol, Avon) $2015 ; 30(1): 28-32$.

6. Heyrman L, Desloovere K, Molenaers G, Verheyden G, Klingels K, Monbaliu E et al. Clinical characteristics of impaired trunk control in children with spastic cerebral palsy. Research in developmental disabilities 2013;34(1):327-34.

7. Cromwell R, Schurter J, Shelton S, Vora S. Head stabilization strategies in the sagittal $1991 ; 85(1): 208-17$

9. Horak FB, Macpherson JM. Postural orientation and equilibrium. In: Rowell LB, 
317 Shepherd JT, editors. Handbook of Physiology, section 12, Exercise: Regulation and

318 Integration of Multiple Systems. New York: Oxford University Press; 1996. p 255-92.

319 10. Pavao SL, Silva FP, Savelsbergh GJ, Rocha NA. Use of sensory information during

320 postural control in children with cerebral palsy: systematic review. J Mot Behav

$3212015 ; 47(4): 291-301$.

322 11. Baldan AM, Alouche SR, Araujo IM, Freitas SM. Effect of light touch on postural sway in individuals with balance problems: A systematic review. Gait Posture 2014;40(1):110.

12. Johannsen L, Wing AM, Hatzitaki V. Contrasting effects of finger and shoulder interpersonal light touch on standing balance. J Neurophysiol 2012;107(1):216-25.

13. Sofianidis G, Hatzitaki V, Grouios G, Johannsen L, Wing A. Somatosensory driven interpersonal synchrony during rhythmic sway. Hum Mov Sci 2012;31(3):553-66. Interpersonal Touch as an Aid to Balance Control in Neurologic Conditions. Rehabil Nurs 2014.

15. Krishnamoorthy V, Slijper H, Latash ML. Effects of different types of light touch on postural sway. Exp Brain Res 2002;147(1):71-9. improves stability during standing. Exp Brain Res 2001;136(4):514-22.

336 17. Mergner T, Maurer C, Peterka RJ. A multisensory posture control model of human 337 upright stance. Prog Brain Res 2003;142:189-201.

338 18. Palisano RJ, Hanna SE, Rosenbaum PL, Russell DJ, Walter SD, Wood EP et al. 339 Validation of a model of gross motor function for children with cerebral palsy. Phys Ther $340 \quad 2000 ; 80(10): 974-85$.

341 19. Ledebt A, Bril B, Wiener-Vacher S. Trunk and head stabilization during the first 
Interpersonal contact in individuals with $\mathrm{CP}$

342 months of independent walking. Neuroreport 1995;6(13):1737-40.

343 20. Wallard L, Bril B, Dietrich G, Kerlirzin Y, Bredin J. The role of head stabilization in

344 locomotion in children with cerebral palsy. Annals of physical and rehabilitation medicine

$345 \quad 2012 ; 55(9-10): 590-600$.

346 21. Dirks T, Blauw-Hospers CH, Hulshof LJ, Hadders-Algra M. Differences between the

347 family-centered "COPCA" program and traditional infant physical therapy based on

348 neurodevelopmental treatment principles. Phys Ther 2011;91(9):1303-22.

349 22. Allum JH, Carpenter MG. A speedy solution for balance and gait analysis: angular

350 velocity measured at the centre of body mass. Curr Opin Neurol 2005;18(1):15-21. 
Interpersonal contact in individuals with $\mathrm{CP}$

\section{Conflict of interest}

354 There are no conflicts of interest to be reported in association with this study.

355 
Interpersonal contact in individuals with $\mathrm{CP}$

356 Tables.

357

358 Table 1.

359 Demographic and clinical information of all participants. 
Interpersonal contact in individuals with CP

360 Figure legends.

361

362 Figure 1.

363 (A) Four of the five testing conditions demonstrated on an individual with cerebral palsy

364 (left) by a therapist (right). Deliberately light interpersonal touch (IPT) was provided to three

365 contact locations: thoracic, occiput and apex (experimental conditions; control conditions:

366 paired walking). The individual with CP is wearing trunk and pelvis parts of an IMU sensor

367 suit (not a thoracolumbosacral orthosis). (B) Illustrative IMU sensor traces of a single CP

368 participant. The upper three panels show transformed trunk angular velocity around a

369 sensor's roll, pitch and yaw axes for paired walking (straight line) and thoracic IPT (dashed

370 line). In order to prevent angular flip-overs between $-180^{\circ}$ to $180^{\circ}$ from distorting the

371 variability measure, sensor orientation angles were cosinus-transformed before differentiation

$372(\cos (\alpha) / s)$.

373

374 Figure 2.

375 The average head (A) and trunk (B) velocity sway as a function of testing condition and

376 group, expressed as the resultant, direction-unspecific standard deviation (SD) of the angular

377 velocity of the respective sensor. Error bars represent the standard error of the mean. Brackets

378 and asterisks indicate statistically significant differences $(+: \mathrm{p}<0.10 ; *: \mathrm{p}<0.05 ; * *: \mathrm{p}<0.01$;

$379 * * *: p<0.001$ ) between testing conditions (experimental conditions: thoracic, occiput and

380 apex; control conditions: alone and paired walking). 
Table 1.

Demographic and clinical information of all participants.

\begin{tabular}{|c|c|c|c|c|c|c|c|c|c|}
\hline Group & Participant & $\begin{array}{c}\text { Age } \\
\text { (years) }\end{array}$ & $\begin{array}{c}\text { Height } \\
(\mathrm{cm})\end{array}$ & $\begin{array}{c}\text { Weight } \\
(\mathrm{kg})\end{array}$ & Gender & Dominance & GMFCS & Symptom I & Symptom II \\
\hline TD & 1 & 14 & 175 & 60 & M & R & & & \\
\hline TD & 2 & 11 & 149 & 37 & F & R & & & \\
\hline TD & 3 & 13 & 160 & 52 & M & L & & & \\
\hline TD & 4 & 15 & 186 & 68 & M & L & & & \\
\hline TD & 5 & 17 & 169 & 53 & F & R & & & \\
\hline TD & 6 & 11 & 149 & 41 & F & L & & & \\
\hline TD & 7 & 13 & 165 & 58 & F & R & & & \\
\hline TD & 8 & 9 & 146 & 32 & F & R & & & \\
\hline TD & 9 & 6 & 126 & 25 & F & R & & & \\
\hline TD & 10 & 6 & 126 & 26 & F & R & & & \\
\hline TD & 11 & 9 & 151 & 42 & F & R & & & \\
\hline TD & 12 & 7 & 123 & 25 & M & R & & & \\
\hline TD & 13 & 8 & 137 & 35 & F & R & & & \\
\hline TD & 14 & 11 & 159 & 38 & F & L & & & \\
\hline TD & 15 & 14 & 170 & 50 & M & R & & & \\
\hline TD & 16 & 9 & 140 & 30 & M & R & & & \\
\hline TD & 17 & 8 & 128 & 22 & F & R & & & \\
\hline TD & 18 & 12 & 152 & 46 & M & R & & & \\
\hline TD & 19 & 11 & 148 & 38 & F & R & & & \\
\hline TD & 20 & 5 & 111.5 & 20 & M & R & & & \\
\hline TD & 21 & 17 & 176 & 63 & F & R & & & \\
\hline TD & 22 & 12 & 180 & 50 & M & L & & & \\
\hline TD & 23 & 13 & 165 & 46 & F & R & & & \\
\hline TD & 24 & 11 & 150 & 44 & M & R & & & \\
\hline TD & 25 & 10 & 148 & 37 & M & R & & & \\
\hline
\end{tabular}




\begin{tabular}{|c|c|c|c|c|c|c|c|c|c|}
\hline $\mathrm{TD}$ & 26 & 13 & 166 & 59 & $\mathrm{~F}$ & $\mathrm{R}$ & & & \\
\hline TD & 27 & 4 & 110 & 18 & $\mathrm{M}$ & $\mathrm{R}$ & & & \\
\hline TD & 28 & 17 & 188 & 83 & $\mathrm{M}$ & $\mathrm{R}$ & & & \\
\hline $\mathrm{TD}$ & 29 & 18 & 170 & 60 & $\mathrm{~F}$ & $\mathrm{R}$ & & & \\
\hline TD & 30 & 8 & 130 & 28 & $\mathrm{~F}$ & $\mathrm{R}$ & & & \\
\hline $\mathrm{TD}$ & 31 & 5 & 116 & 22 & $\mathrm{~F}$ & $\mathrm{R}$ & & & \\
\hline $\mathrm{TD}$ & 32 & 19 & 174 & 65 & $\mathrm{M}$ & $\mathrm{L}$ & & & \\
\hline $\mathrm{TD}$ & 33 & 6 & 107 & 16 & $\mathrm{~F}$ & $\mathrm{R}$ & & & \\
\hline $\mathrm{TD}$ & 34 & 3 & 100 & 17 & $\mathrm{M}$ & $\mathrm{L}$ & & & \\
\hline $\mathrm{TD}$ & 35 & 6 & 120 & 20 & $\mathrm{~F}$ & $\mathrm{R}$ & & & \\
\hline $\mathrm{TD}$ & 36 & 4 & 108 & 21 & $\mathrm{~F}$ & $\mathrm{~L}$ & & & \\
\hline $\mathrm{TD}$ & 37 & 6 & 119.5 & 20 & $\mathrm{~F}$ & $\mathrm{R}$ & & & \\
\hline $\mathrm{TD}$ & 38 & 6 & 124 & 17 & $\mathrm{~F}$ & $\mathrm{R}$ & & & \\
\hline $\mathrm{TD}$ & 39 & 4 & 102 & 16 & $\mathrm{M}$ & $\mathrm{L}$ & & & \\
\hline $\mathrm{CP}$ & 1 & 7 & 116 & 17 & $\mathrm{M}$ & $\mathrm{R}$ & $\mathrm{I}$ & 4 & 2 \\
\hline $\mathrm{CP}$ & 2 & 6 & 116 & 26 & $\mathrm{~F}$ & $N A$ & III & 4 & 2 \\
\hline $\mathrm{CP}$ & 3 & 4 & 111 & 19 & $\mathrm{M}$ & $\mathrm{L}$ & II & 1 & 1 \\
\hline $\mathrm{CP}$ & 4 & 6 & 118 & 18 & $\mathrm{~F}$ & $\mathrm{R}$ & $\mathrm{I}$ & 1 & 1 \\
\hline $\mathrm{CP}$ & 5 & 7 & 113 & 18 & $\mathrm{~F}$ & $\mathrm{R}$ & II & 4 & 1 \\
\hline $\mathrm{CP}$ & 6 & 4 & 107 & 15 & $\mathrm{~F}$ & $\mathrm{R}$ & II & 2 & 1 \\
\hline $\mathrm{CP}$ & 7 & 6 & 110 & 17 & $\mathrm{M}$ & $\mathrm{L}$ & II & 2 & 1 \\
\hline $\mathrm{CP}$ & 8 & 6 & 121 & 26 & $\mathrm{~F}$ & $\mathrm{~L}$ & $\mathrm{I}$ & 1 & 1 \\
\hline $\mathrm{CP}$ & 9 & 5 & 99 & 15 & $\mathrm{M}$ & $\mathrm{R}$ & II & 4 & 2 \\
\hline $\mathrm{CP}$ & 10 & 12 & 145 & 43 & $\mathrm{~F}$ & $N A$ & II & 2 & 1 \\
\hline $\mathrm{CP}$ & 11 & 10 & 141 & 44 & $\mathrm{~F}$ & $\mathrm{~L}$ & II & 2 & 1 \\
\hline $\mathrm{CP}$ & 12 & 8 & 119 & 22 & $\mathrm{M}$ & $\mathrm{R}$ & III & 2 & 1 \\
\hline $\mathrm{CP}$ & 13 & 9 & 139 & 27 & $\mathrm{~F}$ & $N A$ & II & 4 & 2 \\
\hline $\mathrm{CP}$ & 14 & 14 & 162 & 44 & $\mathrm{M}$ & $\mathrm{L}$ & II & 3 & 1 \\
\hline
\end{tabular}




\begin{tabular}{|c|c|c|c|c|c|c|c|c|c|}
\hline $\mathrm{CP}$ & 15 & 10 & 145 & 56 & $\mathrm{~F}$ & $\mathrm{~L}$ & I & 2 & 1 \\
\hline $\mathrm{CP}$ & 16 & 12 & 141 & 29 & $\mathrm{M}$ & $\mathrm{L}$ & III & 2 & 1 \\
\hline $\mathrm{CP}$ & 17 & 9 & 135 & 34 & $\mathrm{M}$ & $\mathrm{L}$ & I & 2 & 1 \\
\hline $\mathrm{CP}$ & 18 & 13 & 164 & 61 & $\mathrm{M}$ & $\mathrm{L}$ & $\mathrm{I}$ & 2 & 1 \\
\hline $\mathrm{CP}$ & 19 & 10 & 145 & 38 & $\mathrm{M}$ & $\mathrm{R}$ & II & 2 & 1 \\
\hline $\mathrm{CP}$ & 20 & 18 & 159 & 51 & $\mathrm{~F}$ & $\mathrm{R}$ & I & 4 & 1 \\
\hline $\mathrm{CP}$ & 21 & 8 & 112 & 20 & $\mathrm{~F}$ & $\mathrm{~L}$ & II & 2 & 1 \\
\hline $\mathrm{CP}$ & 22 & 7 & 110 & 19 & $\mathrm{M}$ & $N A$ & III & 2 & 1 \\
\hline $\mathrm{CP}$ & 23 & 12 & 150 & 39 & $\mathrm{M}$ & $\mathrm{R}$ & II & 3 & 1 \\
\hline $\mathrm{CP}$ & 24 & 19 & 171 & 84 & $\mathrm{M}$ & $\mathrm{R}$ & $\mathrm{I}$ & 1 & 1 \\
\hline $\mathrm{CP}$ & 25 & 18 & 172 & 71 & $\mathrm{M}$ & $\mathrm{L}$ & II & 1 & 1 \\
\hline $\mathrm{CP}$ & 26 & 18 & 163 & 38 & $\mathrm{M}$ & $\mathrm{L}$ & II & 2 & 1 \\
\hline
\end{tabular}

GMFCS: Gross Motor Function Classification System; Symptom I: 1=unilateral, 2=bilateral leg, 3=bilateral arm, 4=bilateral complete; Symptom II:

1=spastic, 2=ataxic; F: female; M: male; R: right; L: left; NA: not available 
A

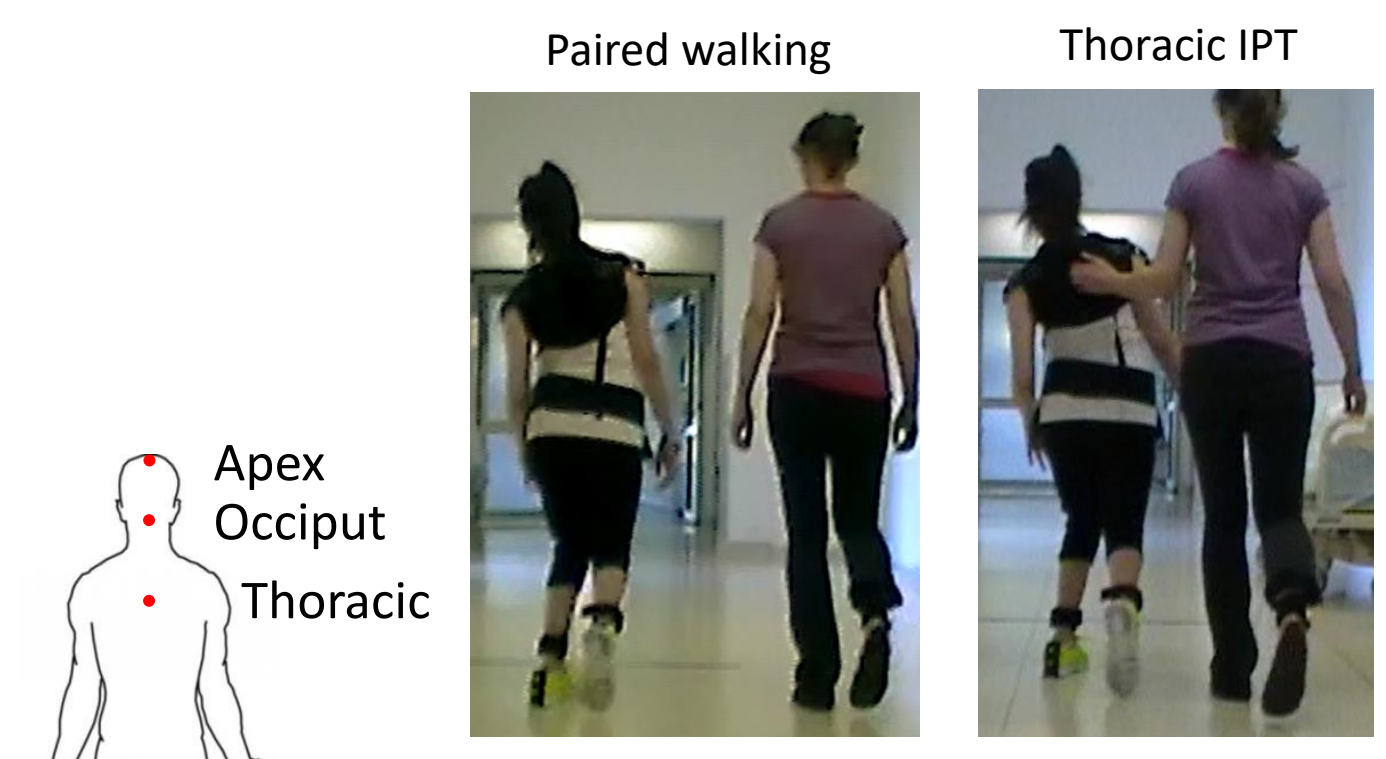

B

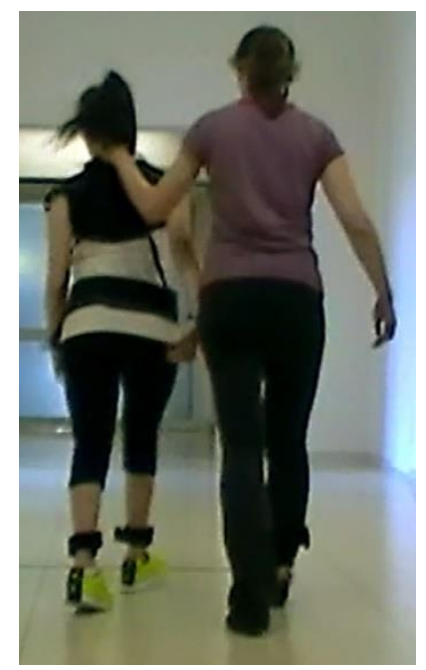

Occiput IPT

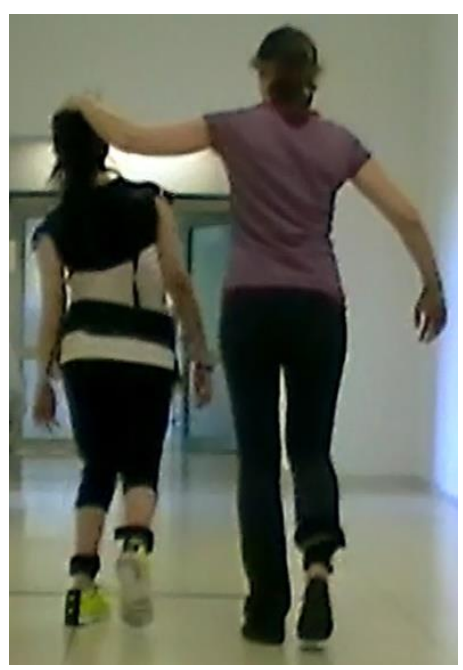

Apex IPT

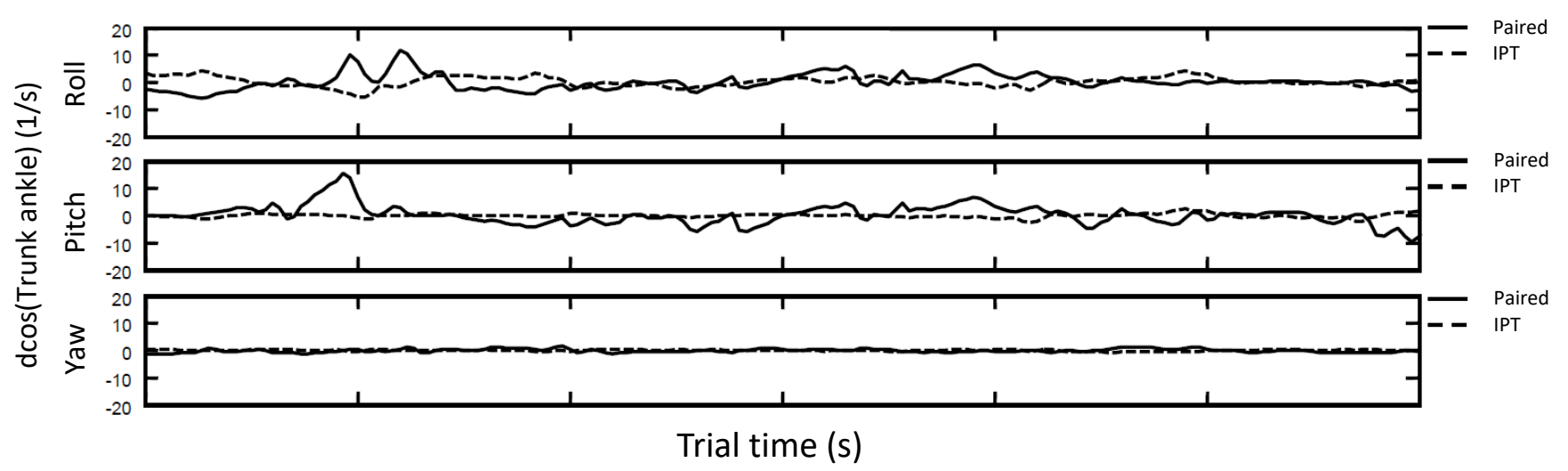

Figure 1. 
A

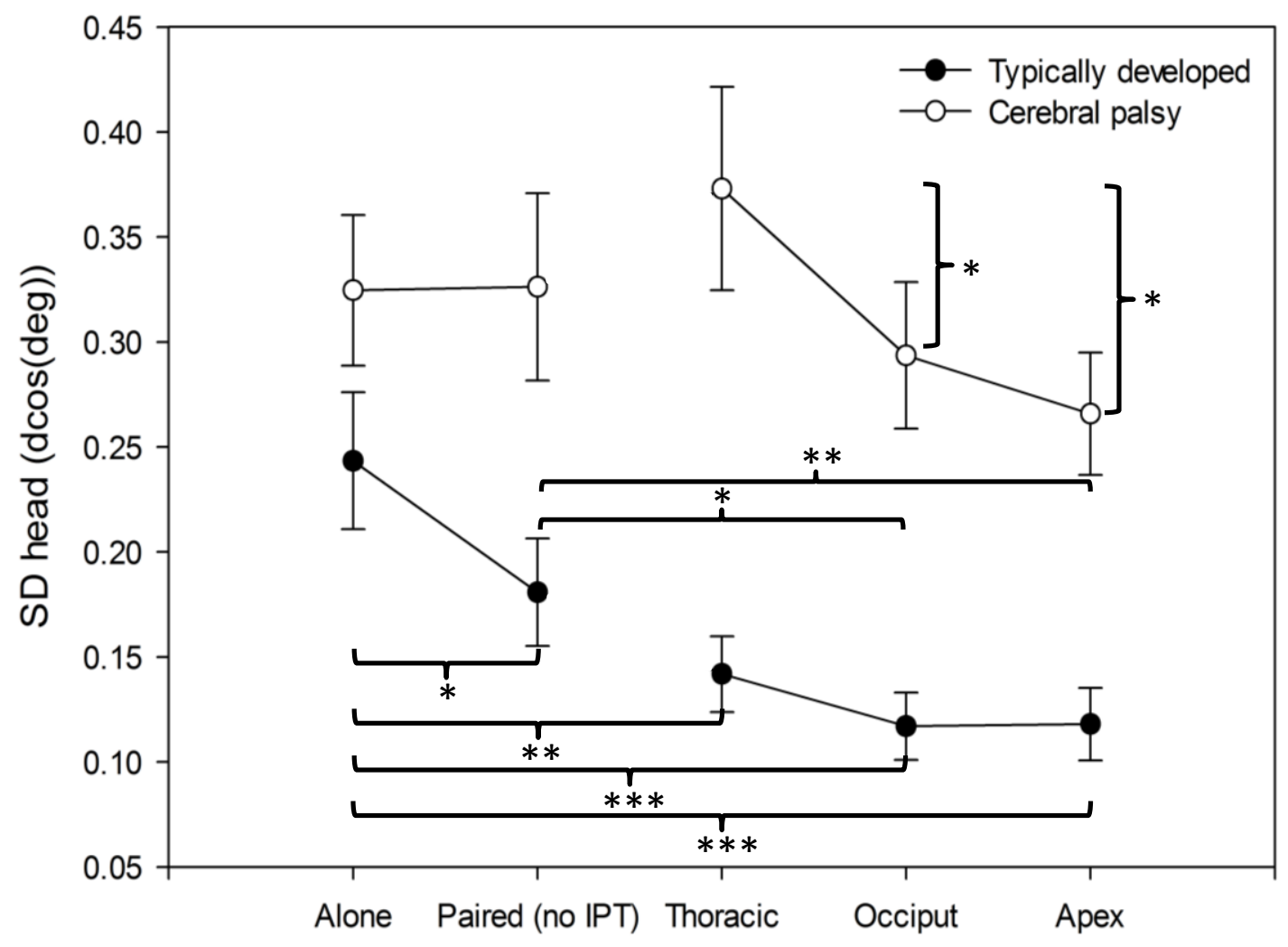

Contact location

B

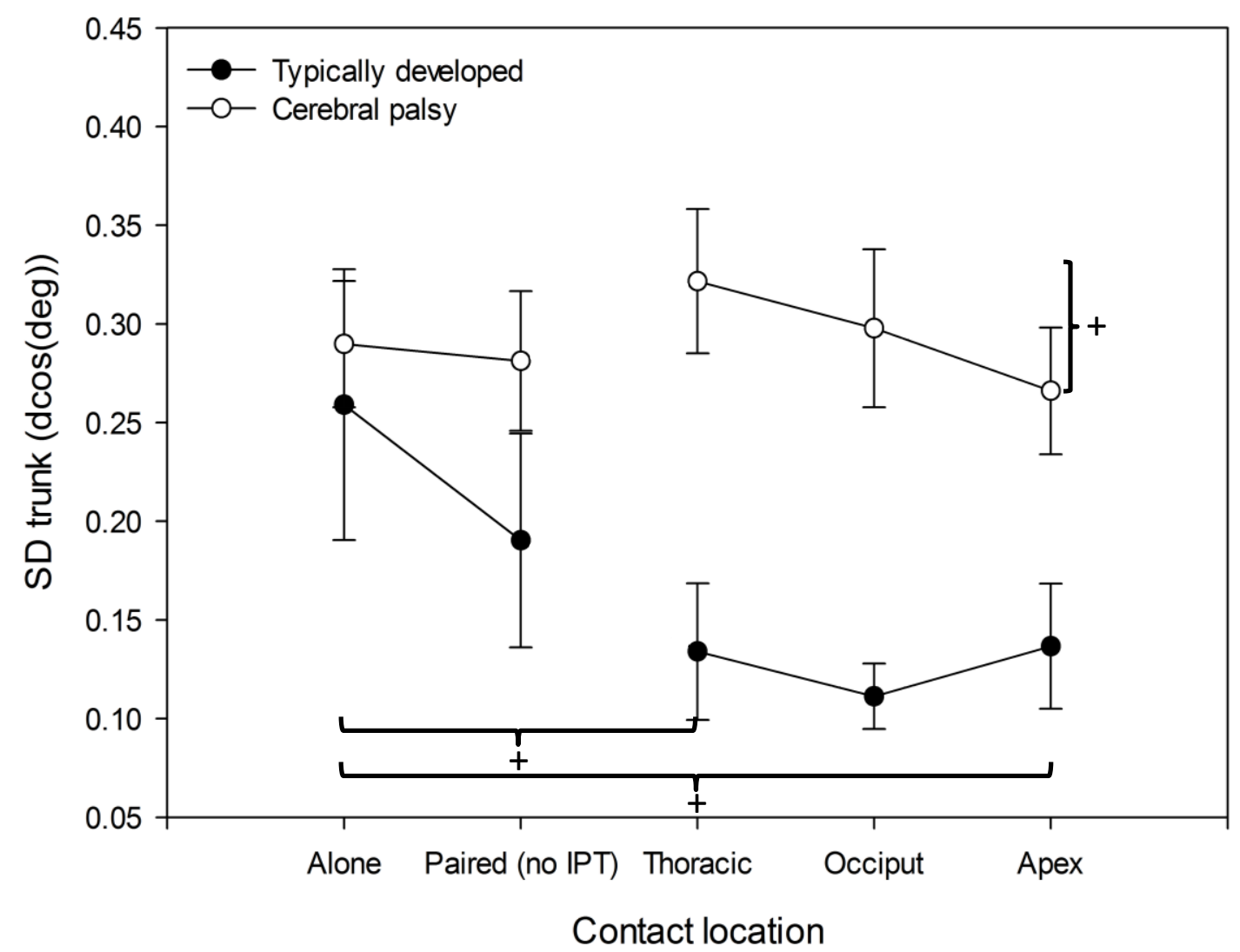

Figure 2. 